\title{
PROCESSO DIDÁTICO METODOLÓGICO PARA PRESCRIÇÃO E CONSTRUÇÃO DE RECURSO DE TECNOLOGIA ASSISTIVA PARA ESTUDANTE COM DEFICIÊNCIA MÚLTIPLA
}

\author{
Mônica Nemézio da Costa Siqueira, Camila Rodrigues Costa, Manoel Osmar Seabra Junior \\ Universidade Estadual Paulista - UNESP, Programa de Pós-Graduação em Educação, Presidente Prudente, SP. E-mail: \\ mncs1985@gmail.com
}

\begin{abstract}
RESUMO
Objetivou-se descrever o processo didático e metodológico para a prescrição e construção de recurso de Tecnologia Assistiva (TA) para um estudante com deficiência múltipla (DMU). Trata-se de uma pesquisa qualitativa e descritiva. Para constituição do processo didático metodológico visando a prescrição e construção do recurso de TA para o estudante com DMU, foram realizados três procedimentos: 1) compreensão das características do estudante (estudo de caso); 2) planificação das ações a serem adotadas (identificação, prescrição e construção da TA); 3) Avaliação da eficiência e eficácia da TA produzida. Neste manuscrito serão apresentados os três primeiros processos. Conclui-se que ao pensar na prescrição e construção de recursos de TA para o estudante com DMU é imprescindível que o professor questione-se a todo momento sobre as ações a serem realizadas e, que possa planificar essas ações de modo a estabelecer parcerias com outros profissionais que o ajudarão a avaliar a eficiência e eficácia da TA para o estudante.

Palavras-chave: Educação Especial. Tecnologia Assistiva. Deficiência Múltipla. Inclusão.
\end{abstract}

\section{METHODOLOGICAL DIDACTIC PROCESS FOR PRESCRIPTION AND CONSTRUCTION OF ASSISTIVE TECHNOLOGY RESOURCE FOR STUDENT WITH MULTIPLE DISABILITY}

\begin{abstract}
The objective was to describe the didactic and methodological process for the prescription and construction of Assistive Technology (TA) resource for a student with multiple disabilities (DMU). This is a qualitative and descriptive research. This is a qualitative and descriptive research. For the constitution of the methodological didactic process aiming at the prescription and construction of the TA resource for the student with DMU, three procedures were performed: 1) understanding of the characteristics of the student (case study); 2) planning of the actions to be adopted (identification, prescription and construction of the TA); It is concluded that when thinking about the prescription and construction of TA resources for students with DMU, it is essential that the teacher is constantly questioning about the and to plan such actions in order to establish partnerships with other professionals that will help you evaluate the effectiveness and effectiveness of TA for the student.
\end{abstract}

Keywords: Special Education. Assistive Technology. Multiple Disability. Inclusion. 


\section{INTRODUÇÃO}

A partir de documentos legais como a Constituição Federal de 1988 (BRASIL, 1988), Declaração de Salamanca (BRASIL, 1994) e, as diretrizes atuais sobre o processo de inclusão presentes na Política Nacional de Educação Especial na Perspectiva da Educação Inclusiva (BRASIL, 2008) houve uma discussão crescente no que tange o processo de inclusão escolar, sobretudo, no que diz respeito à necessidade de garantir acesso, participação e aprendizagem dos estudantes do público-alvo da Educação Especial ${ }^{1}$ na rede regular de ensino.

No caso do presente estudo o estudante possui o diagnóstico de deficiência múltipla (física e cegueira). A deficiência múltipla (DMU) é caracterizada a partir do diagnóstico de uma ou mais deficiências que afetam a funcionalidade de um estudante em relação às atividades de vida independente (AVD), escolares e de relacionamento social (BRASIL, 2000).

Dentre os diferentes comprometimentos que um estudante com DMU pode apresentar, destacam-se as dificuldades associadas ao funcionamento cognitivo, motor e sensorial que exigirá, na maioria dos casos, um apoio permanente ao estudante, sobretudo, para a realização das atividades escolares (ORELOVE; SOBSEY; SILBERMAN, 2005).

A demanda dos estudantes com DMU, faz com que o professor necessite estabelecer estratégias de ensino, identificar e selecionar recursos pedagógicos adequados e/ou adaptados para que o seu estudante desempenhe, com eficiência e eficácia, as várias atividades propostas. No entanto, esse transcurso normal das aulas parece não ser tão tranquilo quando o professor defronta-se com o aluno com DMU, no ensino regular.

Essa situação muitas vezes atrela-se ao desconhecimento de como lidar com esses alunos, ou seja, qual estratégia ou recurso utilizar? Como produzir um recurso para que o mesmo possa se tornar uma Tecnologia Assistiva ${ }^{2}$ (TA) para o estudante?

Neste sentido, o presente estudo tem como problemática: quais são os caminhos que o professor pode estabelecer para pensar na identificação, prescrição e construção de recursos de TA para estudante com DMU?

Desta forma, objetivou-se descrever o processo didático e metodológico para a prescrição e construção de recurso de Tecnologia Assistiva para um estudante com deficiência múltipla.

\section{MÉTODO}

A presente pesquisa caracterizou-se como uma pesquisa qualitativa e descritiva. A pesquisa qualitativa não se preocupa com a representatividade numérica, mas, sim, com o aprofundamento da compreensão de um grupo social, de uma organização, entre outros (GERHARDT; SILVEIRA, 2009). A pesquisa descritiva exige do investigador uma série de informações sobre o que deseja pesquisar. Esse tipo de estudo pretende descrever os fatos e fenômenos de determinada realidade (GERHARDT; SILVEIRA, 2009). A pesquisa está cadastrada no comitê de ética em Pesquisa da Universidade Estadual Paulista, Campus de Presidente Prudente, sob o número do protocolo (CAAE: 94698218.0.0000.5402).

Para constituição do processo didático metodológico visando a prescrição e construção do recurso de TA para o estudante com DMU, foram realizados quatro procedimentos: 1) compreensão das características do estudante (estudo de caso); 2) planificação das ações a serem adotadas (identificação, prescrição e construção da TA); 3) Avaliação da eficiência e eficácia da TA produzida (essa etapa não será apresentada neste estudo. Contudo, no presente estudo sugere-se os caminhos pelo qual o professor poderá avaliar a TA).

\footnotetext{
${ }^{1}$ Segundo a Política Nacional de Educação Especial na Perspectiva da Educação Inclusiva compreende-se como público-alvo estudantes com: Deficiência (física, sensorial, múltipla); Transtornos Globais do Desenvolvimento e Altas Habilidades/ Superdotação (BRASIL, 2008).

${ }^{2}$ No presente estudo o termo Tecnologia Assistiva é compreendido a partir da definição estabelecida pelo Comitê de Ajudas Técnicas (CAT, 2007): "[..] é uma área do conhecimento, de característica interdisciplinar, que engloba produtos, recursos, metodologias, estratégias, práticas e serviços que objetivam promover a funcionalidade, relacionada à atividade e participação, de pessoas com deficiência, incapacidades ou mobilidade reduzida, visando sua autonomia, independência, qualidade de vida e inclusão social" (BRASIL, 2007).
} 
1) Compreensão das características do estudante (estudo de caso): neste momento o professor deverá compreender as características do estudante. Para tanto, podem ser realizados alguns indagamentos pensando em aspectos como aspectos motores e cognitivos, tais como: o estudante possui mobilidade de membros superiores? Qual é a amplitude de movimento? Consegue realizar preensão manual? Como o estudante realiza a preensão manual? Necessita de algum recurso para apoio físico? Compreende de maneira satisfatória o comando verbal do professor? Qual o feedback do estudante em relação a atividade proposta? (entender a situação). No caso do estudante do presente estudo as características identificadas foram:

- Comprometimento de membros inferiores, estudante usuário de cadeira de rodas;

- Estudante diagnosticado com paralisia cerebral;

- Deficiência visual (cego);

- Comprometimentos nas habilidades manipulativas; dificultando a aquisição da leitura no sistema braille;

- Linguagem oral funcional.

Desta forma, percebeu-se que o estudante necessitava de TA que pudesse estimular o desenvolvimento de habilidades manuais para discriminação tátil e que the possibilitasse realizar atividades de vida independente a partir do aprimoramento da sua coordenação motora fina. Observa-se que as necessidades e interesses do estudante foram questionados com o mesmo e os resultados identificados geraram indicativos para o trabalho manipulativo, uma vez que este se interessa por aprender braile e soroban.

2) planificação das ações a serem adotadas (identificação, prescrição e construção da TA): neste momento o professor deverá lançar mão de parcerias com demais profissionais, como por exemplo, fisioterapeuta, terapeuta ocupacional, professor do atendimento Educacional Especializado, entre outros. Além disso, o professor deverá indagar-se: esse recurso atenderá a necessidade do estudante? Quais materiais irei precisar para a construção (customização) da TA? Esse material é de baixo ou alto custo? Onde posso encontrar este material? Este recurso irá expor o estudante a algum risco em termos de segurança? Ou expõe o estudante em relação a estética? O recurso proporcionará funcionalidade para o estudante? Se não for funcional, por qual material ele poderia ser substituído ou quais adaptações poderiam ser utilizadas? E, por fim, este recurso necessitou de muitas adaptações? Quantas? Ele atende a ideia do desenho universal, ou seja, é um recurso que pode ser utilizado para todos os estudantes, com ou sem deficiência?

3) Avaliação da eficiência e eficácia da TA produzida: essa etapa ainda não foi realizada. Contudo, sugere-se alguns caminhos que o professor poderá realizar para avaliar a TA. A avaliação da TA deve pautar-se em oito princípios, a saber: 1) Não encorajar ou exigir movimentos inapropriado durante o seu uso? 2) Não desprender grande gasto energético durante a utilização; 3) Ser seguro e confortável para o usuário; 4) Ter baixo custo e alta resolutividade das necessidades do usuário; 5) Ser de fácil manutenção e uso; 6) Ser personalizado às necessidades do usuário; 7) Ser durável; 8) Ter boa aceitação social ou invisibilidade relativa.

\section{RESULTADOS}

A seguir serão apresentados alguns exemplos de recursos de baixa TA que foram produzidos para o estudante com DMU e que podem subsidiar o trabalho docente a partir da geração de novas ideias que atenda o seu estudante. 
Tabela 1. Recursos Pedagógicos produzidos.

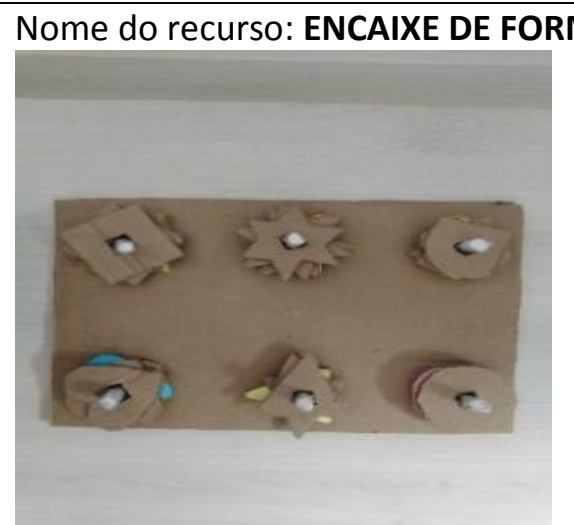

Fonte: Recurso pedagógico do acervo LETAIA.

\section{Descrição do recurso:}

Retângulo de papelão com base reforçada por duas placas de papelão, medindo $34 \mathrm{~cm} \times 25$ $\mathrm{cm}$, com seis pinos distribuídos em sua superfície, com distância de $10 \mathrm{~cm}$ entre as fileiras de pinos, sendo duas fileiras. De uma fileira para outra há $16 \mathrm{~cm}$ de distância. Os pinos são revestidos com fita adesiva transparente.

São dispostas seis diferentes formas, para serem agrupadas de acordo com suas características. Uma mesma forma terá mais de um exemplar, para que o usuário realize a classificação.

Cada peça (forma) tem uma perfuração no centro, para encaixar no pino preso à superfície do papelão. Há um exemplar de cada forma fixado junto a base do recurso.

\section{Objetivo/função do recurso:}

Identificar e classificar seis diferentes formas, dispostas na superfície de papelão. $\mathrm{O}$ usuário deve localizar na superfície do papelão a forma igual a que está segurando. Precisará reconhecer a perfuração no centro da forma e encaixar no pino, que está preso na base de papelão.

Desenvolver habilidades manipulativas, para reconhecer e encaixar as formas adequadamente.

Identificar e agrupar as formas semelhantes nos espaços;

Aprimorar a motricidade fina.

\section{Nome do recurso: ALINHAVO COM CANUDOS.}

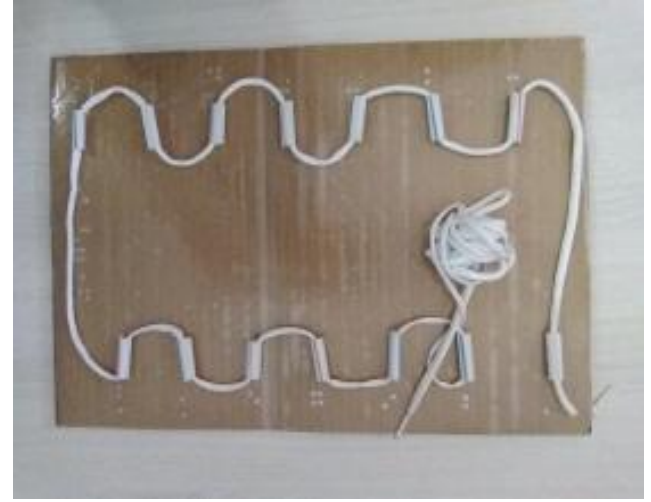

Público - alvo:

O recurso destina-se a estudantes com deficiência visual (cego), com a necessidade de estimulação para o desenvolvimento de habilidades manipulativas e a leitura braile.

Fonte: Recurso pedagógico do acervo LETAIA.

\section{Descrição do recurso:}

Base feita em papelão com $41 \mathrm{~cm} \times 28 \mathrm{~cm}$, com canudos de $3,5 \mathrm{~cm}$ de comprimento, tendo 5 $\mathrm{cm}$ de distância entre os canudos de uma mesma fileira, distribuídos em duas fileiras, com 14 $\mathrm{cm}$ de espaço entre elas, os canudos estão fixados com linha de nylon. Há indicação em braille em cada canudo e sobre a sequência que deve ser seguida. $O$ cadarço para o alinhavo está fixado na base do recurso, indicando onde a tarefa se inicia. Para completar o alinhavo é necessário 1 metro de cadarço. 
Os pontos em braille indicam a direção do alinhavo e foram confeccionados com cola glitter.

\section{Objetivo/função do recurso:}

Explorar a base do alinhavo, para reconhecer onde a tarefa deve iniciar, a sequência de canudos por onde o cadarço deve passar.

Estimular o desenvolvimento da leitura braille e movimentos de coordenação motora fina .

Nome do recurso: PASSA FORMAS COM CORDA

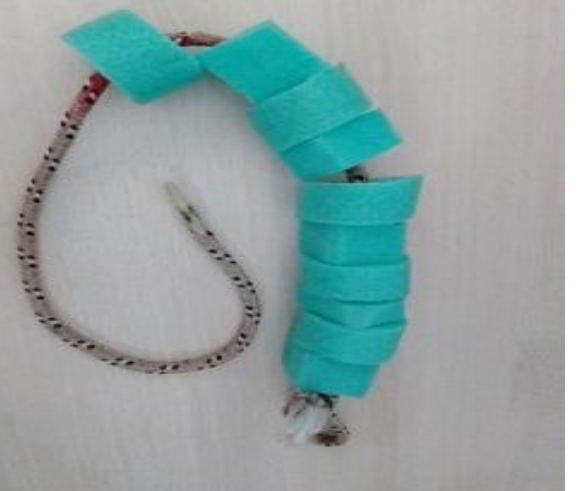

Público - alvo:

$O$ recurso destina-se a estudantes com deficiência visual (cego), com a necessidade de estimulação para o desenvolvimento de habilidades manipulativas.

Sugere-se a utilização deste recurso a estudante com deficiência múltipla que tenha necessidade de estimulacão

Fonte: Recurso pedagógico do acervo LETAIA.

\section{Descrição do recurso:}

Formas geométricas medindo $5 \mathrm{~cm}$, com espumas flutuantes para práticas aquáticas (espaguete) perfuradas no centro. Corda de $70 \mathrm{~cm}$, transpassada no centro das formas geométricas. Sendo três diferentes formas.

Há marcação para que o usuário identifique e diferencie as pontas da corda, como início e fim da tarefa.

\section{Objetivo/função do recurso:}

Reconhecer e manusear determinadas formas geométricas de acordo com estímulos propostos pelo professor.

Desenvolvimento de habilidade manipulativa por meio do encaixe do centro da forma geométrica na corda.

Nome do recurSO: DADO DE FORMAS EM RELEVO COM ESTÍMULO SONORO.

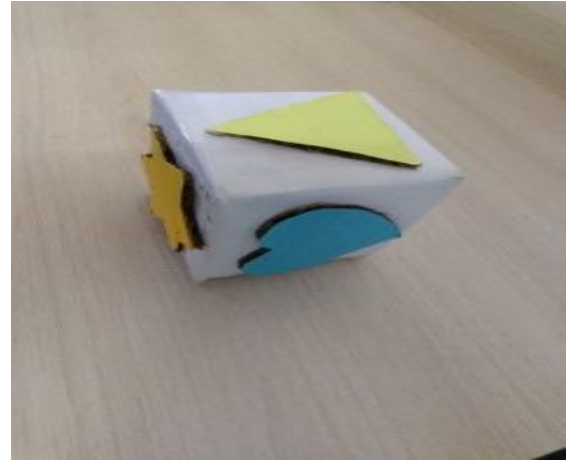

Fonte: Recurso pedagógico do acervo LETAIA.
Público - alvo:

O recurso destina-se a estudantes com deficiência visual (cego), com a necessidade de estimulação para o desenvolvimento de habilidades manipulativas e auditivas quanto a localização do objeto.

Sugere-se a utilização deste recurso a estudante com deficiência múltipla que tenha necessidade de estimulação motora de membros superiores. 


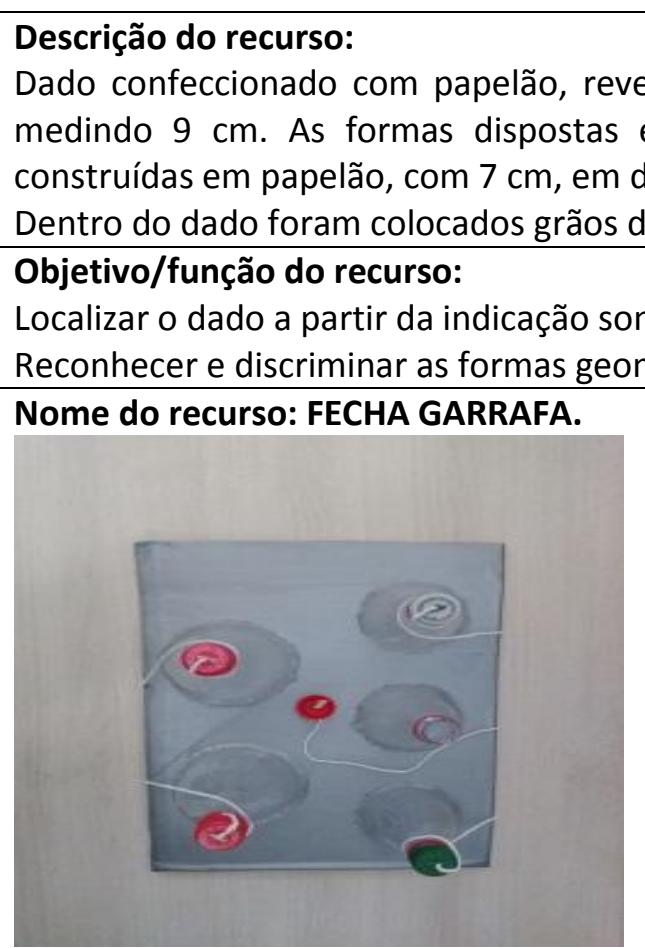

Fonte: Recurso pedagógico do acervo LETAIA.

\section{Público - alvo:}

O recurso destina-se a estudantes com deficiência visual (cego), com a necessidade de estimulação para o desenvolvimento de habilidades manipulativas, coordenação motora fina.

Sugere-se a utilização deste recurso a estudantes com transtorno do espectro autista, com necessidade de estimulação

\section{Descrição do recurso:}

A base do recurso foi construída com papelão, medindo $41 \mathrm{~cm} \times 28 \mathrm{~cm}$, revestida com fita adesiva de cor cinza.

As partes superiores de garrafas pets são fixadas em uma base de papelão, com cola de silicone, foram utilizadas 5 garrafas.

As tampas das garrafas pets são amarradas com barbantes. Os barbantes com $20 \mathrm{~cm}$ de comprimento, estão fixados na base do recurso.

\section{Objetivo/função do recurso:}

Estimular as habilidades manipulativas por meio do movimento giratório de rosquear as tampas.

Nome do recurso: ENCAIXE DE FORMAS.

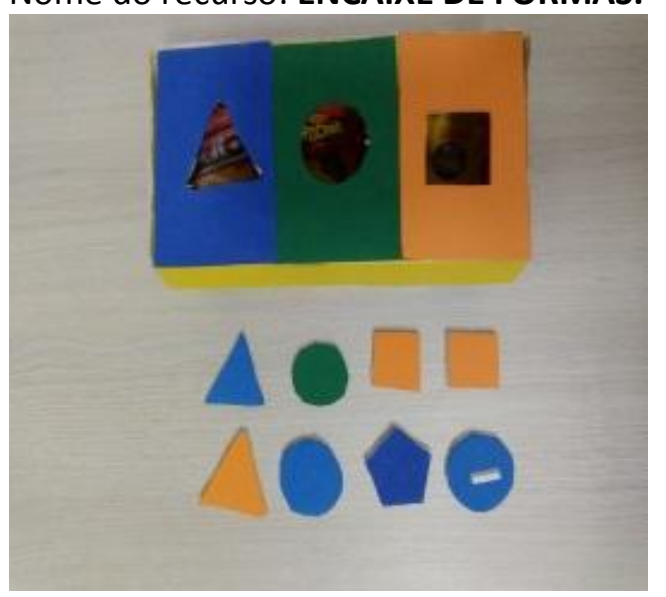

Público - alvo:

O recurso destina-se a estudantes com deficiência visual (cego), com a necessidade de estimulação para o desenvolvimento de habilidades manipulativas.

Fonte: Recurso pedagógico do acervo LETAIA. 


\section{Descrição do recurso:}

Caixa retangular medindo $21 \mathrm{~cm}$ de comprimento, por $10,5 \mathrm{~cm}$ de largura e $6 \mathrm{~cm}$ de altura. $o$ Revestimento da caixa foi confeccionado em EVA.

Em sua base estão indicadas três diferentes formas geométricas: triângulo, círculo e quadrado; nas cores azul, verde e laranja, respectivamente.

A abertura na base do recurso tem a as especificidades de cada forma geométrica, medindo 4 $\mathrm{cm}$. As peças para encaixe foram construídas com EVA, isopor e papel.

\section{Objetivo/função do recurso:}

Estabelecer correspondência das propriedades de três diferentes formas geométricas, comparando ao espaço específico que cada uma deverá ser encaixada.

Nome do recurso: PAREAMENTO DE TEXTURAS.

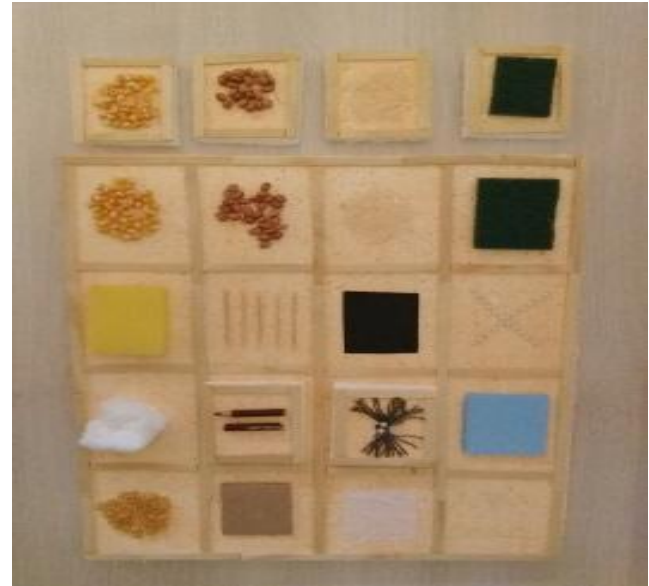

Público - alvo:

O recurso destina-se a estudantes com deficiência visual (cego), com a necessidade de estimulação para o desenvolvimento de habilidades manipulativas e percepção tátil.

Fonte: Recurso pedagógico do acervo LETAIA.

\section{Descrição do recurso:}

Base feita de isopor com $2 \mathrm{~cm}$ de espessura, medindo $44 \mathrm{~cm} \times 36 \mathrm{~cm}$. A base é dividida com 16 espaços de tamanhos iguais, separados com palitos de sorvete que estão fixados na base. São apresentadas 16 diferentes texturas.

As peças para o pareamento foram construídas em isopor com $2 \mathrm{~cm}$ de espessura, sendo quadrados de $8 \mathrm{~cm}$, com suas margens delimitadas por palitos de sorvete.

\section{Objetivo/função do recurso:}

Desenvolver a percepção tátil do estudante, por meio do pareamento entre as peças do recurso.

Nome do recurso: PRANCHA EM BRAILLE PARA OPERAÇÕES MATEMÁTICAS.

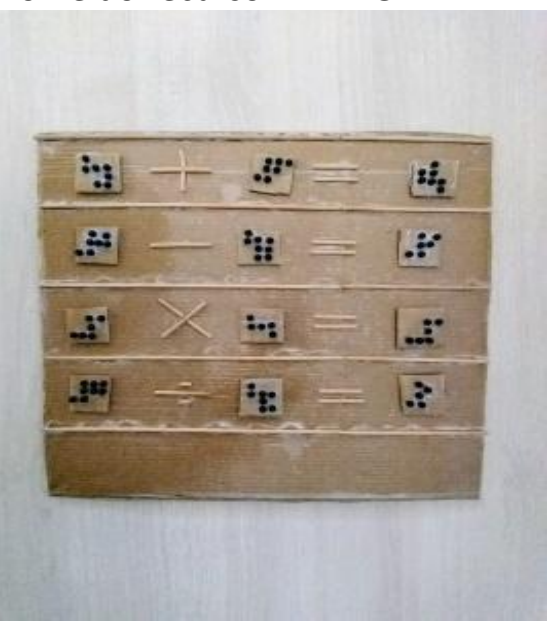

\section{Público - alvo:}

O recurso destina-se a estudantes com deficiência visual (cego), com a necessidade de estimulação para o desenvolvimento de habilidades manipulativas, coordenação motora fina. Treino do Braille.

Fonte: Recurso pedagógico do acervo LETAIA. 


\section{Descrição do recurso:}

Base retangular de papelão medindo $36 \mathrm{~cm} \times 35 \mathrm{~cm}$. As separações na base do recurso são confeccionadas com palitos de churrasco, sinalizando as 4 operações matemáticas e o sinal de igual.

As peças são confeccionadas com papelão, em formato retangular, medindo $6 \mathrm{~cm} \times 5 \mathrm{~cm}$. Os pontos braille estão representados por alfinetes com base arredondada (pinos).

\section{Objetivo/função do recurso:}

Reconhecer as quatro operações matemáticas: adição subtração, multiplicação e divisão com sistema de numeração braille.

Desenvolver o raciocínio lógico matemático para resolver as operações, e simultaneamente ampliar as competências para utilização do sistema Braille.

Fonte: Autores, 2018.

\section{DISCUSSÃO}

Produzir um recurso de baixa tecnologia não exige do professor recursos sofisticados, pois a confecção pode ser realizada de modo artesanal e personalizada diante da necessidade do estudante (BRACCIALLI, 2007; SORO CAMATES, 2003; SUÀREZ, 2003).

Ao pensar na prescrição e produção da TA é imprescindível que haja um envolvimento de profissionais de diferentes áreas e que possam participar de todas as etapas que envolvem este processo (REGANHAN, 2014).

Pode-se refletir que a: escolha do recurso mais eficaz para o estudante tem que levar em consideração as especificidades do estudante, sua participação, motivação e interesse e, sobretudo, a possibilidade de proporcionar condições adequadas para que o estudante possa ser funcional na realização das atividades propostas.

\section{CONCLUSÃO}

Pode-se concluir que ao pensar na prescrição e construção de recursos de TA para o estudante com DMU é imprescindível que o professor questione-se e preveja, a todo momento, sobre as ações a serem realizadas e, que possa planificar essas ações de modo a estabelecer parcerias com outros profissionais que o ajudarão a avaliar a eficiência e eficácia da TA para 0 estudante.

\section{REFERÊNCIAS}

BRACCIALLI, L. M. P. Tecnologia assistiva: perspectiva de qualidade de vida para pessoas com deficiência. In: Vilarta, R.; Guierrez, G.L.; Carvalho, T.H.P.F.; Gonçalves, A. (Org.). Qualidade de vida e novas tecnologias. Campinas: IPES, 2007, p. 105-114.

BRASIL. Constituição (1988). Constituição da república federativa do brasil: promulgada em 5 de outubro de 1988. Organização do texto: Juarez de Oliveira. 4. ed. São Paulo: Saraiva, 1990. 168 p. (Série Legislação Brasileira). Disponível em:

<http://www.planalto.gov.br/ccivil_03/constituicao/constituicao.htm>. Acesso em: 10 ago. 2018.

BRASIL. Ministério dos Direitos Humanos. Secretaria de Direitos Humanos. Secretaria Nacional de Promoção dos Direitos das Pessoas com Deficiência. Declaração de Salamanca e linha de ação sobre necessidades educativas especiais. Brasília: Coordenadoria Nacional para integração da pessoa portadora de deficiência, 1994. Disponível em:<http://portal.mec.gov.br/seesp/arquivos/pdf/salamanca.pdf>. Acesso em: 10 ago. 2018. 
BRASIL. Ministério da Educação. Secretaria de Educação Especial. Programa de capacitação de recursos humanos do ensino fundamental deficiência múltipla. Brasília: MEC/SEE, 2000.

Disponível em:<http://portal.mec.gov.br/seesp/arquivos/pdf/def_multipla_1.pdf>. Acesso em: 17 ago. 2018.

GERHARDT, T.; SILVEIRA, D. T. Métodos de Pesquisa. Porto Alegre: Editora da UFRGS, 2009.

ORELOVE, F. P.; SOBSEY, R. ; SILBERMAN, R. K. Educating children with multiple disabilities: a collaborative approach. Baltimore: P.H. Brookes Publishing Company, 2004.

REGANHAN, W. G. Uso de recursos de baixa tecnologia que favorecem a aprendizagem do aluno com deficiência inserido no ensino regular. Revista Adapta, Presidente Prudente, v. 10, n.1, p. 4146, 2014.

SORO-CAMATS, E. Uso de ajudas técnicas para a comunicação, o jogo, a mobilidade e o controle do meio: uma abordagem habilitadora. In: ALMIRALL, C. B.; SOROCAMATS, E.; BULTÓ, C. R. (Org.). Sistemas de sinais e ajudas técnicas para a comunicação alternativa e a escrita: princípios teóricos e aplicações. São Paulo: Livraria Santos Editora, 2003. p. 23-41.

SUÀREZ, M. D. et al. Ajudas de alta tecnologia para o acesso a comunicação e a escrita. In: ALMIRALL, C. B.; SORO-CAMATS, E.; BULTÓ, C. R. (Org.). Sistemas de sinais e ajudas técnicas para a comunicação alternativa e a escrita: princípios teóricos e aplicações. São Paulo: Livraria Santos Editora, 2003. p. 43-61. 